\title{
Bladder Function Retrieval in Patients with UrinaryTract Dysfunction Following Traumatic Spinal Cord Injury, A Systemic Review
}

\author{
Eyad Faizo* \\ Department of Neurosurgery and spine surgery, Murnau Hospital; Germany
}

Submission: May 14,2018; Published: August 09, 2018

*Corresponding author: Eyad Faizo, Department of Neurosurgery and spine surgery, Murnau Hospital, Germany; Email: dr.eyad.faizo@gmail.com

\author{
Abstract \\ Objectives: To assess the safety and efficacy of different anticholinergic medications for bladder function retrieval following traumatic \\ spinal injury.
}

Methods: A systematic search via MEDLINE, CENTRAL, and CINAHL (Cumulative Index to Nursing and Allied Health Literature), using term: spinal cord injury, and anticholinergic. We excluded studies without a urodynamic study or in different languages than English.

Results: About 15 articles were included in the data synthesis. Median time since injury was 10 years (IQR: 7-21). Clean Intermittent Catheterization (CIC) was most commonly used (39\%). Transurethral catheter use and continent urinary diversions were more prevalent among women. Patients with higher age and indwelling catheter use versus CIC were associated with a higher impact of complications.

Conclusions: Anticholinergic drugs remain crucial medications for controlling urinary incontinence following traumatic SCI. The efficacy of different anticholinergic medications is well proved through their safety profile, with a great success in the rehabilitation period.

Keywords: Spinal cord injuries; neurogenic bladder; Quality of life; Long-term care; Clean intermittent catheterization; Women; Patients; Micturition center; Urinary tract; Rehabilitation; Mobility; Solifenacin, trospium chloride; Anticholinergic; Neurosurgeon; Propiverine; Tolerability; Leak point pressure; Hyperreflexia; Frequency

Abbreviations: CIC: Clean Intermittent Catheterization; PTBD: Post-Traumatic Bladder Dysfunction; NDO: Neurogenic Detrusor Overactivity; SCI: Spinal Cord Injury; QoL: Quality of Life; ER: Extended-Release; IR: Immediate-Release; NDO: Neurogenic Detrusor Overactivity; LPP: Leak Point Pressure; CICV: Clean Intermittent Catheterization Volume;

\section{Introduction}

The pontine micturition center is the final rely of the transmitted signals from the bladder through the spinal cord. A traumatic spinal cord injury may result in interruption of such signals resulting in a various form of neurogenic lower urinary tract dysfunction including detrusor overactivity, atonic bladder, and sphincter insufficiency. Bladder dysfunction is accompanied by a different form of urological complications such as incontinence versus retention of urine; or hydronephrosis, urolithiasis, uremia and poor quality of life.

Preservation of bladder function during rehabilitation period carries an important part of the rehabilitation process. A compliant bladder with a reasonable storage and infrequent voiding would maintain a proper lifestyle for those patients as well as prevention of the frequent urinary tract infections episodes. Different methods have been used as conservative techniques for bladder-emptying including Crede technique, Clean Intermittent Catheterization (CIC), or application of a self-retaining urethral catheter and less commonly a suprapubic catheter.

There are rarely used, surgical alternatives for bladder emptying failure; including sacral anterior root stimulation, incontinent or continent urinary diversions. Despite the major advances in spinal cord injury surgeries, but bladder dysfunction preserves a constant headache against all rehabilitation efforts and advances in surgical treatment among people with SCI. Urinary tract infection is considered the leading cause for readmission after traumatic SCI. The rate of rehospitalization was significantly higher at year 1,5 , and 20 for those who were discharged to a skilled nursing facility after acute rehabilitation. Practitioners and trainees in physical medicine and rehabilitation are aiming to provide a formulation of a rehabilitation plan based on functional goals by the level of injury. Such a plan includes mobility, activities of daily living, equipment needs, and adjustment issues after injury. 


\section{Open Access Journal of Neurology \& Neurosurgery}

The rate of death related to spinal cord injury was examined by Frankel $\mathrm{H}$ and colleagues showing the leading cause of death was related to the respiratory system; urinary deaths ranked second followed by heart disease-related deaths, but patterns in causes of death changed over time. In the early decades of injury, urinary deaths ranked first, heart disease deaths second and respiratory deaths third. In the last two decades of injury, respiratory deaths ranked first, heart-related deaths were second, injury-related deaths ranked third and urinary deaths fourth

The incidence of calculi (kidney and/or ureter) was $1.5 \%$ at 1-year follow-up and $1.9 \%$ at 5 years and was more frequent in patients with complete tetraplegia. Intermittent catheterization was the most common method of bladder management among patients with paraplegia but became less common at later postinjury visits. Spinal cord injury level would be a demarcation step in terms of what type of incontinence may manifest. Above the sacral spinal cord (supra-sacral spinal cord injury) or at or below the sacral spinal cord.

Anticholinergic drugs remain crucial medications for controlling urinary incontinence following traumatic SCI via relaxation of the detrusor muscle. The efficacy of different anticholinergic medications and their safety profile is of a great importance for the success of the rehabilitation period in the SCI population. In this article, we are reviewing the prospective and randomized trials studying anticholinergic therapy for neurogenic bladder dysfunction following traumatic spinal cord injury method A systematic search was conducted through Medline database with the aim to identify as many studies on the topic bladder function retrieval following traumatic spine injury. A comprehensive search was applied utilizing identified search terms including spinal cord injury, CIC, oxybutynin, tolterodine, darifenacin, solifenacin, trospium chloride, and anticholinergic.

The inclusion criteria for article selection were: Prospective clinical trial in English, utilizing at least one anticholinergic medication for patients suffering from spinal cord injury and micturition disorders. The exclusion criteria were: Articles written in a language other than English. A follow up less than 12 months. Searches were performed by a urologist and a neurosurgeon. The abstracts were reviewed to assure their relevance to the subject of the research and if no exclusion criteria were distinguished, the full manuscript was therefore acquired. Appraisals of methodological quality were made by AMSTAR and PRISMA were applied to all meta-analyses found in our search. A total of 27 articles were searched, of which 12 were excluded. The study was based on the remaining 15 articles. Results of different papers were analyzed, and outcomes were classified according to the incidence of complications or the efficacy of the surgery and the achieved physical activities

\section{Results}

Fifteen publications were included in our analysis. A comparison between different anticholinergic agents in treating
Post-Traumatic Bladder Dysfunction (PTBD) was reported by many investigators. They prospectively designed a study for a period of 3 years and successfully consented patients were divided into two groups either for having [1], investigated the effect on urodynamics of 4 weeks treatment with solifenacin succinate in patients with Neurogenic Detrusor Overactivity (NDO) due to Spinal Cord Injury (SCI) and revealed a clear improvement in the Quality of Life (QoL) in the solifenacin arms versus placebo.

Stöhrer M, et al. [2], investigated the Efficacy and tolerability of propiverine Extended-Release (ER) compared with Immediate-Release (IR) were evaluated in patients with proven Neurogenic Detrusor Overactivity (NDO) and demonstrated that there were no significant differences across both groups regarding efficacy and tolerability

Horstmann M, et al. [3], compared doubling the dose of Tolterodine ER or Trospium higher-than-recommended dosage in patients where the manufacturer's recommended dosage had failed and revealed better response with the increased dosage of Tolterodine or Trospium in patients with the traumatic neurogenic bladder.

In Walter P, et al. [4], reported the efficacy of intravesically instilled trospium chloride, is not absorbed into the circulation in significant amounts and, thus, this mode of administration will improve the efficacy of trospium chloride therapy by reducing the side effects. reported utilization of oxybutynin transdermal system (oxybutynin-TDS) in spinal cord injury patients with neurogenic detrusor overactivity and incontinence despite the use of Clean Intermittent Catheterization (CIC) and showed significant improvement at the end of the follow-up.

Amend B, et al. [5,6], reported employment of a dosageescalated monotherapy for patients with neurogenic bladder dysfunction following trauma to the spine and demonstrated a successful treatment for $85 \%$ of the patients who previously demonstrated unsatisfactory outcome. established a prospective study comparing the effectiveness of intravesical oxybutynin, propantheline, and capsaicin in the management of neuropathic bladder following spinal cord injury. More subjects demonstrated improvement with intravesical propantheline than oxybutynin for RV, detrusor Leak Point Pressure (LPP), Clean Intermittent Catheterization Volume (CICV), and LV. This study suggests that intravesical agents may be used as effective adjuvants in the management of incontinence due to neurogenic detrusor overactivity following spinal cord injury.

O'Leary $\mathrm{M}$, et al. $[7,8]$, in a prospectively designed study evaluated the effects and tolerability of extendedrelease oxybutynin chloride on the frequency of voiding and catheterization and urodynamic capacity in Spinal Cord Injury (SCI) patients with defined detrusor hyperreflexia. reported an evaluation for the utilization of Botulinum-A toxin injections into the detrusor, and confirmed to be a safe and valuable therapeutic option in spinal cord injured patients with incontinence resistant 


\section{Open Access Journal of Neurology \& Neurosurgery}

to anticholinergic medication who perform clean intermittent self-catheterization

\section{Discussion}

Overactive bladder is a social bothering disease resulting in frequent urge for urination and combined with an embarrassing urinary leak in some individuals, which is exacerbated by urinary tract infection. The standard first line of care would be conservative in utilizing anticholinergic, urinary antiseptic and frequent or timed voiding. One category of overactive bladder are those with traumatic spinal cord injury, who subjected to a more severe form of such disease, related to the neurologic problem and the inability to walk efficiently. Patients showing signs of failure of urine control would proceed with a permanent or recurrent urethral catheterization with a recognized infection incidence. Clean intermittent catheterization has been considered the golden treatment for difficult cases that have been resistant to pharmacologic treatment. For quite a while, decent outcomes were thought to be reliant on the pharmacologic agents for controlling bladder overactivity in the meantime, the results of the agents have been sub satisfactory in a large category of patients. In this manner, a hypothesis has been generated and widely accepted that escalated increase in the dose of such agents would be more appropriate for controlling the bladder irritability. Intravesical instillation of anticholinergic agents has emerged through the treatment profile of bladder irritability related to traumatic spinal injury without undesired side effects of orally administrated agents. Based on that hypothesis, Schurch B, et al. [8] reported in a prospective cohort study that the utilization of Botulinum-A toxin injections into the detrusor, and confirmed to be a safe and valuable therapeutic option in spinal cord injured patients with incontinence resistant to anticholinergic medication

Walter P, et al. [4], reported the efficacy of intravesically instilled trospium chloride, is not absorbed into the circulation in significant amounts and, thus, this mode of administration will improve the efficacy of trospium chloride therapy by reducing the side effects. O'Leary $\mathrm{M}$, et al. [7], in a prospectively designed study evaluated the effects and tolerability of extendedrelease oxybutynin chloride on the frequency of voiding and catheterization and urodynamic capacity in Spinal Cord Injury (SCI) patients with defined detrusor hyperreflexia [9-14].

In view of our audit of the available peer-reviewed articles, we conclude that anticholinergic agents are reliable and efficient treatment with the lowest side effects, especially the intravesical instillation. However, that technique has its limitations which we summarize as the need for catheterization for the installation of the agent. Thus, because various anticholinergic agents are currently available for treating post-traumatic overactive bladder. We conclude that there is more concrete evidence of the safety and efficacy of increasing dose of these pharmacologic agents for better controlling of such conditions [15-17].

\section{Conclusion}

Anticholinergic therapy improves bladder capacity and suppresses the recurrent urge for micturition. Intravesical instillation of anticholinergic agents represents interesting approaches and seems to show promising results as a pharmacologic treatment of patients with overactive bladder.

\section{References}

1. Amarenco G, Suntory M, Fagertun H, Wright M, Compion G, et al. (2017) Solifenacin is effective and well tolerated in patients with neurogenic detrusor overactivity: preliminary results from the SONIC urodynamic study. Neurourol Urodyn 36(2): 414-421.

2. Stöhrer M, Mürtz G, Kramer G, Warmack W, Primus G, et al. (2007) Propiverine compared to oxybutynin in neurogenic detrusor overactivity-results of a randomized, double-blind, multicentre clinical study. Eur Urol 51(1): 235-242.

3. Horstmann M, Schaefer T, Aguilar Y, Stenzi A, et al. (2006) Neurogenic bladder treatment by doubling the recommended antimuscarinic dosage. Neurourol Urodyn 25(5): 441-445.

4. Walter P, Grosse J, Bihr AM, Kramer G, Schulz HU, et al. (1999) Bioavailability of trospium chloride after intravesical instillation in patients with neurogenic lower urinary tract dysfunction: A pilot study. Neurourol Urodyn 18(5): 447-453.

5. Amend B, Hennenlotter J, Schaffer T, Horstmann M, Stenzl A, et al. (2008) Effective treatment of neurogenic detrusor dysfunction by combined high-dosed antimuscarinics without increased side-effects. Eur Urol 53(5): 1021-1028.

6. George J, Tharion G, Richard J, Macaden AS, Thomas R, et al. (2007) The effectiveness of intravesical oxybutynin, propantheline, and capsaicin in the management of neuropathic bladder following spinal cord injury. Scientific World J 7: 1683-1690.

7. O'Leary M, Erickson J, Smith C, McDermott C, Horton J, et al. (2003) Effect of controlled-release oxybutynin on neurogenic bladder function in spinal cord injury. J Spinal Cord Med 26(2): 159-162.

8. Schurch B, Stöhrer M, Kramer G, Schmid DM, Gaul G, et al. (2000) Botulinum-A toxin for treating detrusor hyperreflexia in spinal cord injured patients: a new alternative to anticholinergic drugs? Preliminary results. J Urol 164(3Pt 1): 692-627.

9. Halaska M, Ralph G, Wiedemann A, Primus G, Ballering-Bruhl B, et al. (2003) Controlled, double-blind, multicentre clinical trial to investigate long-term tolerability and efficacy of trospium chloride in patients with detrusor instability. World J Urol 20(6): 392-399.

10. Sezer N, Akkuş S, Uğurlu FG (2015) Chronic complications of spinal cord injury. World J Orthop 6(1): 24-33.

11. Dejong G, Tian W, Hsieh CH, Jun C, Karam C, et al. (2013) Rehospitalization in the first year of traumatic spinal cord injury after discharge from medical rehabilitation. Arch Phys Med Rehabil 94(4 Suppl): S87-97.

12. Cardenas DD, Hoffman JM, Kirshblum S, McKinley W (2004) Etiology and incidence of rehospitalization after traumatic spinal cord injury: a multicenter analysis. Arch Phys Med Rehabil 85(11): 1757.

13. Frankel HL, Coll JR, Charlifue SW, Whiteneck GG, Gardner BP, et al. (1998) Long-term survival in spinal cord injury: a fifty-year investigation. Spinal Cord 36(4): 266-274.

14. McKinley WO, Jackson AB, Cardenas DD, DeVivo MJ (1999) Long-term medical complications after traumatic spinal cord injury: a regional model systems analysis. Arch Phys Med Rehabil 80(11): 1402-1410. 
15. Madhuvrata P, Singh M, Hasafa Z, Abdel-Fattah M (2012) Anticholinergic drugs for adult neurogenic detrusor overactivity: a systematic review and meta-analysis. Eur Urol 62(5): 816-830.

16. Shea BJ, Hamel C, Wells GA, Bouter LM, Kristjansson E, et al. (2009) AMSTAR is a reliable and valid measurement tool to assess the methodological quality of systematic reviews. J Clin Epidemiol 62(10): 1013-1020.

17. Moher D, Liberati A, Tetzlaff J, Altman DG (2009) Preferred reporting items for systematic reviews and meta-analyses: the PRISMA statement. PLoS Med 6(7): e1000097.

Your next submission with Juniper Publishers
will reach you the below assets
- Quality Editorial service
- Swift Peer Review
- Reprints availability
- E-prints Service
- Manuscript Podcast for convenient understanding
- Global attainment for your research
- Manuscript accessibility in different formats
( Pdf, E-pub, Full Text, Audio)
- Unceasing customer service
Track the below URL for one-step submission
https://juniperpublishers.com/online-submission.php

